\title{
Energy Intensity Diagnostics Contributed to Solar Dryers Energy Challenges
}

\author{
Fateme Esmailie, Mohammad Aminy, and Hossein Ghadamian, Member, IACSIT
}

\begin{abstract}
The energy consumption of dryers as an energy-intensive industry system is discussed in the present paper. In order to reduce this energy amount, solar dryers were applied since ancient times, among these kinds of dryers, high drying rate solar dryers include fluidized bed and spouted bed were discussed in this research study. The experiment and calculation results depicted that, the fluidized bed solar dryer has higher drying rate than spouted bed dryer, even though, spouted bed dryer has less energy intensity consumption.
\end{abstract}

Index Terms-Energy efficiency, fluidized bed, solar dryer, spouted bed.

\section{INTRODUCTION}

Drying is one of the significant parts of every industry that consumes a big amount of energy per year. One of the well-known applications of dryers is drying agricultural products, in order to reduce the fossil fuel energy consumption, one practical way is utilizing solar dryers.

Solar drying was used to dry agricultural products since ancient times. Agricultural products were exposed to the sunlight to dry. This process lasted for a long time and due to the lots of reasons such as weather conditions, insect attack and other pollutants, huge amounts of these products decayed; as a solution several attempts were done on designing and manufacturing solar dryers [1].

Researches were conducted on developing solar dryers; were reviewed by several authors, as an example the solar dryers used for grape drying application were reviewed by Pangavhane and Sawhney in 2002; and by Jiraj, Singh and Srikant in 2009 [2], [3].

Moreover, Murthy reviewed briefly the model and experimental researches which were developed before 2009 [4].

In 2010 Fudholi et al. reviewed the researches were implemented on solar dryers that used to dry agricultural and marine products [5]. In addition, another review paper on solar dryers in this year was published by Lalit et al. which focused on some kind of solar dryers with thermal storage system [6]. Lalit et al. published their second review paper on this topic in 2011 with concentrating on the agricultural products drying application [7].

VijayaVenkataRaman, Iniyan \& Goic reviewed the solar drying technologies in 2011. This study was focused on solar dryers that applied to dry corps in off-shine hours [1].

Manuscript received June 15, 2014; revised August 17, 2014. This Work was supported in part by the Materials and Energy Research Center. Energy intensity diagnostics contributed to solar dryer's energy challenges.

The authors are with the Renewable Energy Department, Materials and Energy Research Center, Iran (e-mail: f.esmaili@merc.ac.ir, mohamedaminy@yahoo.co.uk, h.ghadamian@merc.ac.ir).
The different applications of solar dryers were reviewed by Pirasteh et al. in 2014. This paper consisted of a comprehensive study of industrial and agricultural solar dryer applications, they concluded that solar dryers have a payback period less than 10 years [8].

In 2014 Mustayen et al. compared design, performance and applications of common solar dryers. The dryers which they considered were included: active, passive, direct, indirect and mixed mode solar dryers. This paper evaluated these dryers based on the product quality and economical features [9].

Applying phase change materials in solar dryers was one of the main objects of Shalaby et al. review paper, which was published in 2014. They concluded that systems with utilizing PCM lead to more efficient solar dryers because these materials reduce heat losses [10].

Parkash \& Kumar wrote a survey on solar greenhouse drying, also they presented a model which provided design data, this model could help pick out the optimal dryer [11].

Chua and Chu enumerated the solar dryer as a low cost drying method in developing countries. They selected six types of dryers as low-cost dryers according to three considerations included: 1- low cost manufacturing; 2uncomplicated operation that does not need expert operator and 3-efficient drying processes. These six types selected dryers were: fluidized bed, spouted bed, infrared, solar, simple convective and desiccant drying [12].

According to all above papers solar drying is a cost effective system which can recduce energy consumptions costs, moreover solar dryers can produce dry products with good quality, In spite of these benefits, solar dryers were not successful to pervade in industries. Three significant reasons of this failure include:

1) drying rate of common dryers is low, so in order to dry specific amount of drying samples solar dryers required wider spaces to install in comparison with fossil fuel dryers;

2) Due to instantaneous variations of solar radiation and wind velocity and accordingly unstable ambient temperature, input temperature of solar dryers changes continuously so controlling the drying process is more difficult in compared with industrial dryers;

3) Solar dryers can apply through the region with average daily solar radiation upper than $300 \mathrm{w} / \mathrm{m}^{2}$.

As a need, solar dryers with high drying rate must be studied, so fluidized bed dryer is a choice, but this type of dryer is faced with some challenges that make it difficult to combine this kind of dryer with solar technology. Most important challenges are listed below:

1) Pressure drop through the fluidized bed is high, so a powerful motor drive is required to compensate this 
pressure drop, thus higher electric energy consequently more PV panels are required.

2) Due to the high air velocity, the air residence time in solar collector is low consequently the air temperature cannot increase same as the natural convection scenario; that is governed in traditional solar dryers. Thus fluidized solar dryer is a kind of low temperature dryers.

In order to increase the drying rate of solar dryers and solve first issue, as a first attempt, Aminy and Vali designed, manufactured and tested a solar fluidized bed in 2010, which was located in $\left(35^{\circ} 44^{\prime} 35^{\prime \prime} \mathrm{N}, 50^{\circ} 57^{\prime} 25^{\prime \prime} \mathrm{E}\right)$ coordinates. This system consists of a plenum duct that integrates the collectors exit vent and a centrifugal fan.

\section{OBJECTIVE OF ThIS STUDY}

The mentioned system had the ability to increase drying rate, but it faced with some challenges; this study analyzed four challenges and their solutions related to mentioned solar fluidized bed dryer. The challenges identified are presented as questions below:

1) How much thermal energy required to dry specific amount of grains? Are these collectors able to provide this amount? Are these collectors operating in an acceptable efficiency range?

2) Is it possible to reduce the air pressure drop in the system and accordingly decrease electric energy consumption of centrifugal fan? If so, how doing it?

3) How much electric energy required to fluidize specific amounts of grains? Does this amount supply with renewable energies?

4) Is the dryer bed's geometry efficient or it needs reforming?

The main aim of this study is replying these questions and troubleshooting the solar fluidized bed dryer.

\section{FIRST FLUIDIZED BED SETUP}

As a first troubleshooting procedure step, this system was divided into four sections:

1) Solar collectors

2) Plenum ducts

3) Electrical devices

4) Drying bed

In order to modify the system each parts inspected and tested individually to find defects, then attempts to discover solutions commenced.

\section{A. Solar Collectors}

One set of solar collectors was examined both in natural and forced convection scenarii. In order to fulfill the solar collector performance inspecting a set of experiments was carried out in July 2013. During measurement, temperature and relative humidity ratio were obtained using Tamkar PLC2B data loggers, ENVIT propeller anemometer was used to measure wind speed. Likewise, solar radiations were determined by TES 1333R solar meter and also input \& output velocity profiles were measured by a TES-1341 hotwire anemometer.

Results disclosed that the cover glass of the solar collector has high absorbance and it caused lots of heat losses from the cover, and consequently leads to decrease the solar collector efficiency.

To calculate the required solar collector area following assumptions were considered based on previous study:

1) 315.2 gr corns were loaded in the fluidized bed.

2) Initial moisture content of particles was $70 \%$ (wet basis).

3) Final moisture content of the particle was $13 \%$ (wet basis).

4) Fluidized bed convective heat transfer coefficient assumed to be $240 \mathrm{~W} /\left(\mathrm{m}^{2} . \mathrm{K}\right)$ [13].

5) Input hot air velocity was $1 \mathrm{~m} / \mathrm{s}$.

6) Input cross sectional area in fluidized bed was a circle shape mesh with $19 \mathrm{~cm}$ diameter.

7) The average of solar collector efficiency in forced convection scenario is $40 \%$ based on experiment study and simulation done by Ghadamian et al. [14].

8) The average of solar radiation through the drying period is $700 \mathrm{~W} / \mathrm{m}^{2}$.

9) The total collectors' surface area is $5.4 \mathrm{~m}^{2}$.

10) The loaded particles were dried during 80 minutes.

Related calculations are listed in Table I.

TABLE I: GOVERN EQUATIONS TO CALCULATE THE REQUIRED SOLAR COLLECTOR AREA

\begin{tabular}{|c|c|c|}
\hline Description & Equations & Results \\
\hline $\begin{array}{l}\text { Energy required } \\
\text { for drying special } \\
\text { amount of corn }\end{array}$ & $\begin{array}{l}\mathrm{Q}_{\mathrm{t}}=\mathrm{Q}_{\text {sensitive }}+\mathrm{Q}_{\text {Latent }} \\
=\mathrm{m} \mathrm{Cp} \Delta \mathrm{T}+\mathrm{m} \text { hfg }\end{array}$ & $450.34 \mathrm{~kJ}$ \\
\hline $\begin{array}{l}\text { Energy content of } \\
\text { input hot air }\end{array}$ & $\mathrm{Qq}_{\text {air }}=\mathrm{m} \cdot \mathrm{C}_{\mathrm{p}} \cdot \mathrm{T}=\rho \mathrm{A} \cdot \mathrm{V} \cdot \mathrm{C}_{\mathrm{p}} \mathrm{T}$ & $1288.85 \mathrm{~J} / \mathrm{s}$ \\
\hline $\begin{array}{l}\text { Energy gained by } \\
\text { grains while the } \\
\text { hot air flowing } \\
\text { through the } \\
\text { Fluidized bed }\end{array}$ & $\mathrm{Q}_{\text {air to corn }}=\mathrm{h} . \mathrm{A} \cdot \Delta \mathrm{T}$ & 82.5 watt \\
\hline $\begin{array}{l}\text { Fluidized bed's } \\
\text { Efficiency }\end{array}$ & $\eta_{\text {Fluidized bed }}=\frac{Q_{\text {air to corn }}}{Q_{\text {air }}}$ & 0.064 \\
\hline $\begin{array}{l}\text { Energy that must } \\
\text { be supplied by } \\
\text { the collector }\end{array}$ & $\dot{Q}=\frac{Q_{t}}{\eta_{\text {Fluidized bed }} \times t}$ & 1.54 Watt \\
\hline $\begin{array}{c}\text { Collector area } \\
\text { required }\end{array}$ & Collector Efficiency $=\frac{\dot{Q}}{A . S}$ & $40 \%$ \\
\hline
\end{tabular}

Repeating the calculations assuming the $40 \%$ efficiency for fluidized bed indicated that the solar collector's area required for drying $315.2 \mathrm{gr}$ corns during $80 \mathrm{~min}$ can be 0.8 $\mathrm{m}^{2}$.

\section{B. Plenum Ducts}

As the second step the ducts which linked the output section of centrifugal fan to fluidized bed were tested to evaluate pressure drop occurred through them. This section consisted of a rectangle to circle conversion profile, a $90^{\circ}$ elbow with $18.8 \mathrm{~cm}$ diameter and a circular steel mesh which has small holes in it, that was employed to pass the air, connected the elbow to the bed and prevented the grains fell down into the elbow. Air input and output velocities were monitored in this section.

Moreover, connectors such as elbow, pipes and steel mesh lead to more velocity reduction. Owing to the fact that air is a compressible fluid, this velocity drop would not lead to increase pressure, so the pressure drop occurred through the bed. 
Elbow and connector pipes were eliminated by rotating the centrifugal fan in the vertical direction, and the output section of the fan was connected directly to the fluidized bed to reduce the velocity drop.

The output section surface area of the centrifugal fan is $0.009 \mathrm{~m}^{2}$, so increasing the surface area to $0.03 \mathrm{~m}^{2}$ caused to a reduction in the air velocity, to compensate this amount, more energy must consume in the motor drive part, due to prevent the area increasing, a plate which had a $8 \mathrm{~cm}$ diameter hole on it were applied instead of the a rectangle to circle conversion profile.

Experimental results in both scenarii (Vertical and Horizontal direction of centrifugal fan) are included in Table II.

TABLE II: POWER AND VELOCITY COMPARISON WITH SETUPS

\begin{tabular}{llll}
\cline { 3 - 3 } & First setup & Improved Setup \\
\hline \hline $\begin{array}{l}\text { Power of motor drive based on } \\
\text { measurement }\end{array}$ & & 30 watt \\
$\begin{array}{l}\text { Output air velocity based on } \\
\text { measurement }\end{array}$ & $1 \mathrm{~m} / \mathrm{s}$ & $7 \mathrm{~m} / \mathrm{s}$ \\
\hline \hline
\end{tabular}

Results depicted that reducing connectors and decreasing the input area of the fluidized bed, were effective solutions to reduce the velocity drop (air velocity is a critical parameter in the fluidized bed apparatus).

\section{Electrical Devices}

A 370 Watt AC electric motor was used to drive the centrifugal fan and supply velocity required to fluidized corn grains. The electrical energy consumed by this motor was supplied by power network. To detect the real energy consumption of this motor, the current and potential difference of the motor was monitored; while the system was under load. The Potential difference of the motor was adjusted manually; the motor Potential difference was reduced step by step. In each run the output air temperature and velocity were recorded, as the minimum fluidizing velocity for specified amount of corn was determined before, so the experiment lasted until the output air velocity was more than minimum fluidizing air velocity or the motor began to work down. The minimum power consumption of the motor was calculated from this set of experiments. The experiment results are included in Table III.

TABLE III: ELECTRICAL MOTOR CHARACTERIZATION THROUGH WORKING CONDITIONS

\begin{tabular}{lllll}
\hline \hline Current(A) & Potential(v) & Velocity(m/s) & Temp® & Power(watt) \\
\hline 0.76 & 219 & 13.5 & & 166.44 \\
0.75 & 222 & 12.5 & 33 & 166.5 \\
0.77 & 198 & 12 & 32.9 & 152.46 \\
0.75 & 170 & 10.1 & 35.8 & 127.5 \\
0.77 & 152 & 9.2 & 38.9 & 117.04 \\
0.77 & 138 & 8.3 & 40.3 & 106.26 \\
0.77 & 127 & 7.5 & 41.5 & 97.79 \\
0.72 & 109 & 5.9 & 43 & 78.48 \\
0.44 & 70 & 3.5 & & 30.8 \\
\hline \hline
\end{tabular}

An intuitive check specified that the motor drive which applied to this system was designed for implying force to water and it must be utilized as the water pump, as a result this motor derive was not working at its appropriate operating condition, the mentioned derive had the 370 watt nominal power consumption, but the experiments depicted that it just consumed 78.5 watt energy which provided from the power network.

\section{Drying Bed}

Finally, input air temperature and velocity of the cylinder bed with and without corn grains were recorded to calculate the pressure and temperature drop through the bed.

Due to increase in the bed diameter in comparison with the centrifugal fan output section, the air velocity drop was occurred in the bed, on the other hand, decreasing the bed diameter resulted to increase the bed depth and consequently increase the pressure drop, so it must deliberate to find the best practice bed diameter.

By decreasing the bed's diameter less electrical energy is required but the initial loading mass must be reduced, so the drying rate will be decreased, since this research focused on the energy aspect; the bed with $8 \mathrm{~cm}$ diameter and less drying rate was selected.

To solve the drying rate reduction issue, spouted bed was selected instead of fluidized bed, which has fewer velocity drops in comparison with the fluidized bed. In general, in the same conditions, spouted bed has lower electrical energy consumption (lower minimum spouting velocity) in comparison with fluidized bed, on the contrary, fluidized bed has higher drying rate than spouted bed [15].

\section{FIX DEFECTS}

According to the previous section, in order to improve the solar fluidized bed dryer, the following activities were done: 1) A $0.8 \mathrm{~m}^{2}$ solar collector air heater which contained solar glass (which had suitable features to apply for solar systems) was substituted with the three solar air heater collectors with total area equal to $5.4 \mathrm{~m}^{2}$.

2) The output section of centrifugal fan was rotated $90^{\circ}$ and covered with a rectangular plate, which an $8 \mathrm{~cm}^{2}$ diameter circle was cut off from that according the Fig. 1. This profile led to eliminate elbow and also decrease the bed's diameter and consequently decrease the reduction in air velocity.

3) A 30 watt DC electric motor was substituted with 370 AC motor drive. The power required to drive the replaced motor was provided from a 60 watt PV module.

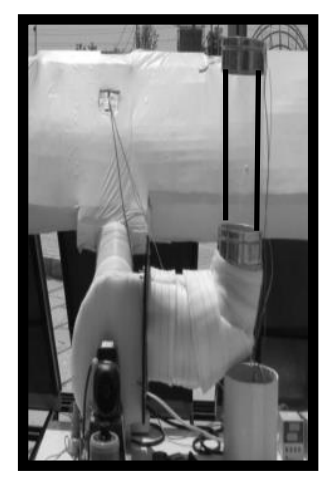

(a)

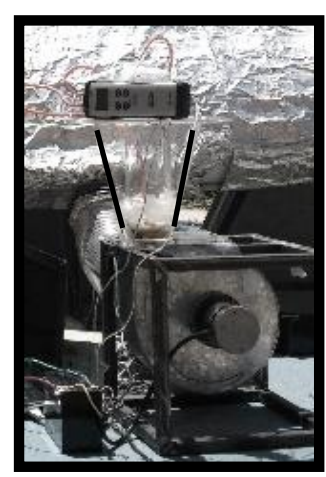

(b)
Fig. 1. (a) Pilot 1 includes fluidized bed, elbow, connector pipes; (b) Pilot 2 includes spouted bed without any extra connectors. 
4) The fluidized bed was substituted with a spouted bed.

As criterions, drying rate, Thermal energy consumption, Electrical energy consumption and Total energy consumption were calculated. Governed equations to calculate the mentioned parameters are listed in Table IV.

TABLE IV: GOVERnED EQUATIONS TO CALCULATE THE COMPARATIVE PARAMETERS

\begin{tabular}{llc}
\hline \hline $\begin{array}{l}\text { Equation } \\
\text { NO. }\end{array}$ & $\begin{array}{l}\text { Comparative } \\
\text { parameters }\end{array}$ & Equations \\
\hline 1 & Drying rate & \multicolumn{1}{c}{$\begin{array}{c}m_{\text {vapored water }} \\
t_{d}\end{array}$} \\
2 & $\begin{array}{l}\text { Thermal energy } \\
\text { consumption }\end{array}$ & $Q_{t h}=G_{T} \times A_{c} \times \eta_{\text {collector }} \times t_{d}$ \\
3 & $\begin{array}{l}\text { Electrical energy } \\
\text { consumption } \\
\text { Total energy } \\
\text { consumption }\end{array}$ & $Q_{e}=I \times V \times t_{d}$ \\
\hline \hline
\end{tabular}

Table $\mathrm{V}$ includes the Comparative parameters for both fluidized and spouted bed.

TABLE V: COMPARATIVE PARAMETERS' VALUE

\begin{tabular}{lll}
\hline \hline $\begin{array}{l}\text { Comparative } \\
\text { parameters }\end{array}$ & Fluidized bed & Spouted bed \\
\hline Drying rate & $2.2 \mathrm{gr}$ water/min & $0.95 \mathrm{gr}$ water/min \\
$\begin{array}{l}\text { Thermal energy } \\
\text { consumption }\end{array}$ & $7.3 \mathrm{MJ}$ & $1.2 \mathrm{MJ}$ \\
$\begin{array}{l}\text { Electrical energy } \\
\text { consumption }\end{array}$ & $336 \mathrm{~kJ}$ & $162 \mathrm{~kJ}$ \\
$\begin{array}{l}\text { Total energy } \\
\text { consumption }\end{array}$ & $7.64 \mathrm{MJ}$ & $1.4 \mathrm{MJ}$ \\
\hline \hline
\end{tabular}

\section{DISCUSSION}

According to Table IV and Table V it is obvious that the fluidized bed has higher drying rate but spouted bed is a better choice considering energy aspects.

\section{CONCLUSION}

A solar spouted bed dryer with $162 \mathrm{~kJ}$ electrical energy consumption and 1.2 MJ thermal energy was substituted a fluidized bed dryer with $336 \mathrm{~kJ}$ electrical energy consumption and 7.3 MJ thermal energy

However more accurate studies are required to find best practice, in this way modeling and simulating the transport phenomena in each type of these dryers can be useful.

Also, Dynamic nature of solar phenomena needs dynamic models, but most of researches use average parameters in solar researches that cause keeping out of the reality.

Due to reduce heat losses through the process, the hot air which exits from the bed can be recycled and it can be used as preheated air entering the solar collectors, but it has some disadvantages listed below:

1) Recycling the air causes to decrease the mass transfer driving force; because the output hot air has higher moisture content in comparison with the ambient air.

2) Sedimentation is another disadvantage of the air recycling.

3) Enhancing the required electrical energy which consumes by centrifugal fan is one of the other obstacles that the air recycling is faced with.

Fortunately all the barriers mentioned above have practical solutions:

1) Output section of drying bed can be equipped with silica gel which can absorb the humidity of output air. Moreover, the recycling ratio must be calculated exactly.

2) The absorbent plate can be cleaned in regular periods, also filters which installed in the input section of the collector can prevent dust entering.

3) Due to the low density of hot air, required electrical energy will not increase significantly and it is negligible compared with total required energy.

\section{REFERENCES}

[1] S. V. V. Raman, S. Iniyan, and R. Goic, "A review of solar drying technologies," Renewable and Sustainable Energy Reviews, vol. 16, no. 5, pp. 2652-2670, 2012.

[2] K. S. Jairaj et al., "A review of solar dryers developed for grape drying," Solar Energy, vol. 83, no. 9, pp. 1698-1712, 2009.

[3] D. R. Pangavhane and R. L. Sawhney, "Review of research and development work on solar dryers for grape drying," Energy Conversion and Management, vol. 43, no. 1, pp. 45-61, 2002.

[4] M. V. R. Murthy, "A review of new technologies, models and experimental investigations of solar driers," Renewable and Sustainable Energy Reviews, vol. 13, no. 4, pp. 835-844, 2009.

[5] A. Fudholi et al., "Review of solar dryers for agricultural and marine products," Renewable and Sustainable Energy Reviews, vol. 14, no. 1 , pp. 1-30, 2010.

[6] L. M. Bal, S. Satya, and S. N. Naik, "Solar dryer with thermal energy storage systems for drying agricultural food products: A review," Renewable and Sustainable Energy Reviews, vol. 14, no. 8, pp 2298-2314, 2010.

[7] L. M. Bal et al., "Review of solar dryers with latent heat storage systems for agricultural products," Renewable and Sustainable Energy Reviews, vol. 15, no. 1, pp. 876-880, 2011.

[8] G. Pirasteh et al., "A review on development of solar drying applications," Renewable and Sustainable Energy Reviews, vol. 31, pp. 133-148, 2014.

[9] A. G. M. B. Mustayen, S. Mekhilef, and R. Saidur, "Performance study of different solar dryers: A review," Renewable and Sustainable Energy Reviews, vol. 34, pp. 463-470, 2014.

[10] S. M. Shalaby, M. A. Bek, and A. A. El-Sebaii, "Solar dryers with PCM as energy storage medium: A review," Renewable and Sustainable Energy Reviews, vol. 33, pp. 110-116, 2014.

[11] O. Prakash and A. Kumar, "Solar greenhouse drying: A review," Renewable and Sustainable Energy Reviews, vol. 29, pp. 905-910, 2014.

[12] K. J. Chua and S. K. Chou, "Low-cost drying methods for developing countries," Trends in Food Science \& Technology, vol. 14, no. 12, pp. 519-528, 2003.

[13] A. S. Mujumdar, Handbook of Industrial Drying, CRC Press, 2006.

[14] F. Esmailie, H. Ghadamian, and M. Aminy, "Modeling and simulation of a solar flat plate collector as an air heater considering energy efficiency," Mechanics \& Industry, 2014

[15] W. Jittanit, G. Srzednicki, and R. H. Driscoll, "Comparison between fluidized bed and spouted bed drying for seeds," Drying Technology, vol. 31, no. 1, pp. 52-56, 2013.

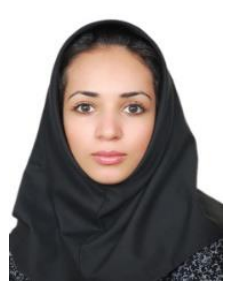

F. Esmailie is a young renewable energy engineer from Iran who was born in Tehran in $21^{\text {th }}$ March 1987. She graduated from Isfahan University of Technology in chemical engineering in June 2009 and she received her master degree in renewable energy from Materials \& Energy Research Center in April 2014.

She worked with professor Hossein Ghadamian, professor Mohammad Aminy and professor Behzad Ahmadi, doing her thesis on the solar spouted bed dryer throughout the last year of her master studies. The project is focused on simulation and testing a solar dryer which has high drying rate and low energy consumption intensity.

Ms. Esmailie currently is working as a research assistant with professor Ghadamian in Materials and Energy Research Center in the subjects about her field like energy modeling within the subjects of Double Skin Façade (DSF) buildings, compact heat exchangers. Her main research interests include modifying renewable energy systems especially solar systems, energy systems integration \& analysis, energy efficiency modifications in buildings and thermal systems simulations. 


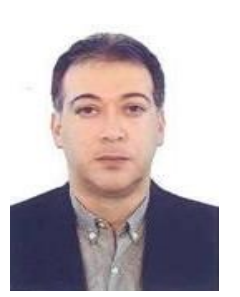

Mohammad Aminy was born in Tehran in $23^{\text {th }}$ of August, 1960. He is a Ph.D. holder in heat transfer in porous media using fluids near their critical region in 1991, received M.Sc. degree in energy studies in 1986 , postgraduate diploma in fuel technology in 1985 and higher national diploma in mechanical engineering in 1984, all in UK.

He has 15 years of experience as deputy head and group manager as well as a member of scientific board in two main research centers in Iran, main working field in alternative fuels and solar system design and construction. Also twenty years of working experience as the head of engineering and technical manager in private sector in the fields of motor industry and high tech. clean room design and construction for various industries. He has been awarded five patents, in the fields of alternative fuel system design and solar systems.

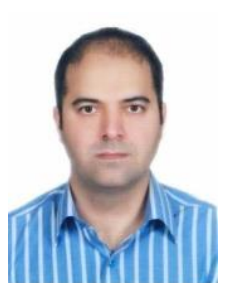

Hossein Ghadamian was born in Tehran in $3^{\text {th }}$ July 1973. He finished his post doctorate fellowship education in the field of industrial gas turbines in Lund University (LTH-Thermal power engineering division) in Sweden in 2008. He received Ph.D. degree in energy engineering in Azad University (Science \& Research Branch) in Iran in 2004, the M.Sc. degree in energy engineering in Azad University (Science \&
Research Branch) in Iran in 1998, B. Eng. Degree in mechanical engineering from Tabriz University (Technology Faculty) in Iran in 1994.

His aim previous works and researches are oriented on modeling \& simulations of energy systems design \& analysis. In Macro scenario provides interdisciplinary decision models to achieve optimizations through non-linear mathematical modeling \& parametric analysis afterwards, considering more technical aspects of development. Whereas, Micro analysis includes dynamic engineering studies within energy efficiencies approach, regarding integration of Renewable Energy into the overall energy system, considering trade-off for sustainability ambitions against performance impacts. Since 2010 up to now, he focused on two scenarii in energy systems approach; first, in energy systems design \& development researches, that he partly engaged with the $\mathrm{CO}_{2}$ capturing and abatemen systems and alternative bio-fuels integrated with SOFC/GT/CHP cycle systems. Second, through with energy models within new technologies \& emission reduction systems and in more details working projects including district heating, desiccant systems and double façades buildings. $\mathrm{He}$ considers $\mathrm{CO}_{2}$ capturing methods, a core for environmental aspects as a valuable emerge key regarding simulation \& modeling in relation with technological point of view.

Prof. Ghadamian also has many passions to teach within energy related courses about energy systems modeling and analysis regarding advanced mathematics to master \& Ph.D. students at academy level and industrial end-users cases. He also has been awarded as a brilliant professor of Azad University among 350 professor members, in 2007. 